\title{
SIMULATING THE EFFECT OF ACCESS ROAD ROUTE SLECTION ON WIND FARM CONSTRUCTION
}

\author{
Khaled Nassar \\ Mohamed El Masry \\ Department of Construction Engineering \\ American University in Cairo \\ Cairo, EGYPT
}

\author{
Hesham Osman \\ Department of Structural Engineering \\ Cairo University \\ Giza, EGYPT
}

\begin{abstract}
Wind energy as a power source is attractive alternative to fossil fuels. Wind farms are typically constructed in undeveloped rural areas with challenging topography. The lack of a paved road network leading to the site and within the site itself pose significant challenges to the planning of wind farm construction. Therefore the selection of the most appropriate access road route is essential in the overall planning of the wind farm construction. This paper presents an overall view of the construction process and will focus on the selection of access road routes to optimize the overall wind farm construction. An integrated framework for wind farm construction is presented and the problem of optimal access road selection is highlighted. A discrete event simulation model is developed for the site construction and the model is used to test the impact of various access road routes on the overall duration of the project. A numeric example is presented along with conclusions, limitations and suggestions for future research.
\end{abstract}

\section{INTRODUCTION}

Wind power is increasingly becoming an important form of alternative energy as it involves conversion of the abundant wind energy into a useful form of energy. Wind energy as a power source is attractive as an alternative to fossil fuels, because it is plentiful, renewable, widely distributed, green, and produces no greenhouse gas emissions. By the end of the year 2009, the world wide capacity of wind-powered generators was 159.2 Giga-watts (GW) (Carns and Bender 2009, 2010). This amount is only expected to grow all over the world as more wind farms are being planned and constructed every day. Wind power often involves constructing large-scale wind farms which are connected to the electric power transmission network. However, the construction of wind farms poses many challenges due to the unique nature of the construction sequence, physical constraints as well as the unique size and area of the construction site. The design and construction of large scale wind farms is relatively new and several important factors of the process need to be studied to optimize the construction plan.

Wind turbine construction is a repetitive construction process that mainly involves lifting large prefabricated components to large heights in high wind speed conditions. Thus, contractors are faced with challenging work environments that impact the time, cost and safety of construction operations (WEC 2007). The unique nature of wind farm construction warrants the development of specific construction planning tools that can be used to plan construction operations at the strategic and tactical levels. As such, this research aims at developing a set of tailored construction planning tools for the wind turbine construction industry. For wind farm contractors, these tools will result in better management of construction risks, more realistic planning, more cost-effective utilization of construction resources, safer work environments, and shortened project durations. For wind farm developers these benefits will simply translate into cheaper wind turbines constructed in shorter durations. Furthermore, contractors need to answer 


\section{Nassar, El Masry, and Osman}

questions like: What sequence should be followed during wind turbine erection?, When is it more cost effective and safe to use multiple cranes for a single lift versus a large crane? What is the best access road route for the wind farm construction? What is the impact of wind?, etc...

Some of the important factors affecting wind farm construction include:

A. Construction of wind farms and especially the lifting operations is highly dependent on wind speed and this is complicated by the uncertainty of the wind forecasts.

B. Wind farms construction involves several crane-dependent operations involving several high lifts. This requires careful selection and utilization of the cranes on site

C. Wind farm construction sites are usually very large and require special planning and management for material delivery and storage

D. Wind farms construction involves several items that need to be fabricated and usually Just-inTime delivery is practiced for these items

E. Wind farm construction involves a relatively small number of highly specialized crews for lifting and assembly

F. Wind farm construction involves extensive access route construction

In particular this paper this paper focuses on the site planning of wind farm construction and the effect of choosing various access road routes on the time of the construction process. The components of a wind turbine are typically prefabricated and transported to site for assembly, which requires the construction of new access roads or the widening and strengthening of existing roads and bridges. Within the wind farm site, temporary access roads that were typically constructed for maintenance equipment now need to accommodate larger transport trucks during construction. With increasing turbine size, the blades and nacelle are becoming larger and heavier, the importance of construction access roads efficiently is essential. Due to the linear nature of wind farm construction in general, the selection of various routes for the access roads will significantly impact the overall schedule. Various access road route options can be chosen for the construction of any wind farm because of the modular arrangement of the wind towers. Access road routes that require the least cut and fill volumes are obviously more desirable in terms of cost and duration. On the other hand, the impact of the selection of the access road routes on the overall schedule is not easily discernable from the earthwork volumes only because of the complex nature of the construction process of wind farms. For example, it may be the case that an access road route is prepared and ready and remain idle because of wind conditions or because of varying productivity rates of succeeding activities. Therefore the selection of the most appropriate access road route is essential in the overall planning of the wind farm construction. This paper will present an overall view of the process and will focus on the selection of access road routes to optimize the overall wind farm construction.

The remainder of this paper is organized as follows; in the next the section the overall framework of the research project is presented. This is followed by a description of the site work sub model and a presentation of the discrete event simulation model that was developed. Then an example problem is presented and finally, conclusions and recommendations are offered.

\section{FRAMEWORK FOR PLANNING AND OPTIMIZING WIND FARM CONSTRUCTION PROJECTS}

This paper presents a portion of a larger framework for physically-based (also called Cyber Physical) simulation of wind farm construction taking into consideration the various processes and resources involved as well as the site topographical conditions. The overall framework is shown in figure 1 . The construction process of the wind farm is simulated using a discrete event simulation tool STROBOSCOPE. The simulation model consists of two main parts. The first sub-model simulates the lifting and assembly process of individual wind turbines while the second sub-model simulates the construction process of the access roads and utilities construction. The combined simulation received input from two three kinds of inputs. The first is the resources in terms of crews, crane configurations, forms used, etc... The second is 
input related to the wind speed prediction, which is processed using neural network and is capable of predicting long term wind speeds as well as gusts. The third is topographic data of the site and alternate access routes which is input from site design and planning software such as Civil 3D. The output is also processes using optimization techniques in order to reach an optimized construction plan, which considers the best combination of resources, access road routes and other variables. This optimization is carried out firstly to develop a comprehensive long term construction plan for the process and then can be adjusted to provide tactical planning decisions during construction. The output from the simulation model is also presented using photorealistic animation through a specially programmed tool called STROBOMAX, which is able to convert trace files from the simulation into 3D Max animations. The main focus of this paper is the site work sub-model (sub-model B), which is presented in the next section.

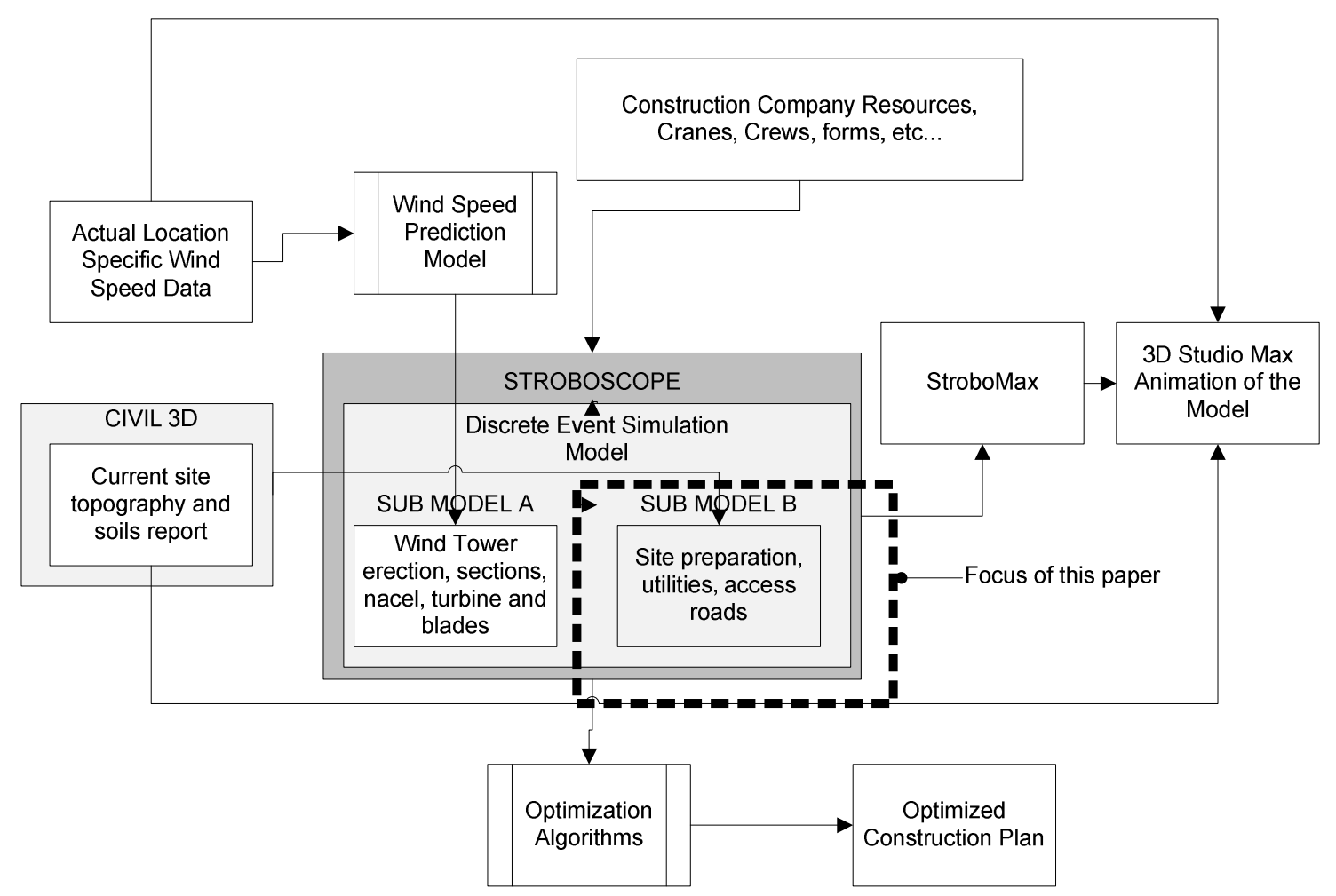

Figure 1: The proposed Overall Framework

\section{DESCRIPTION OF THE SITE WORK SUB-MODEL}

The simulation described here is limited to typical large scale wind farm projects, which typically provides 250 megawatt capacity or more of wind-powered electrical energy with thirty or more wind turbines. The generators are usually connected through underground cables to a central electrical substation, which in turn delivers power to the main power grid. To provide access to each tower, several miles of roads need to be constructed. Wind farms construction in general and wind towers construction in particular can be divided into two main parts; the first part is concerned with the site conditions and preparation of site which depends primarily whether the portion in which the tower will be constructed is a cut or fill section. While the second part is the construction of the tower itself. A simulation for the construction process was developed using a general purpose simulation language geared specifically for construction applications calledSTROBOSCOPE (Martinez 1996). A description of the site work model is presented next. 


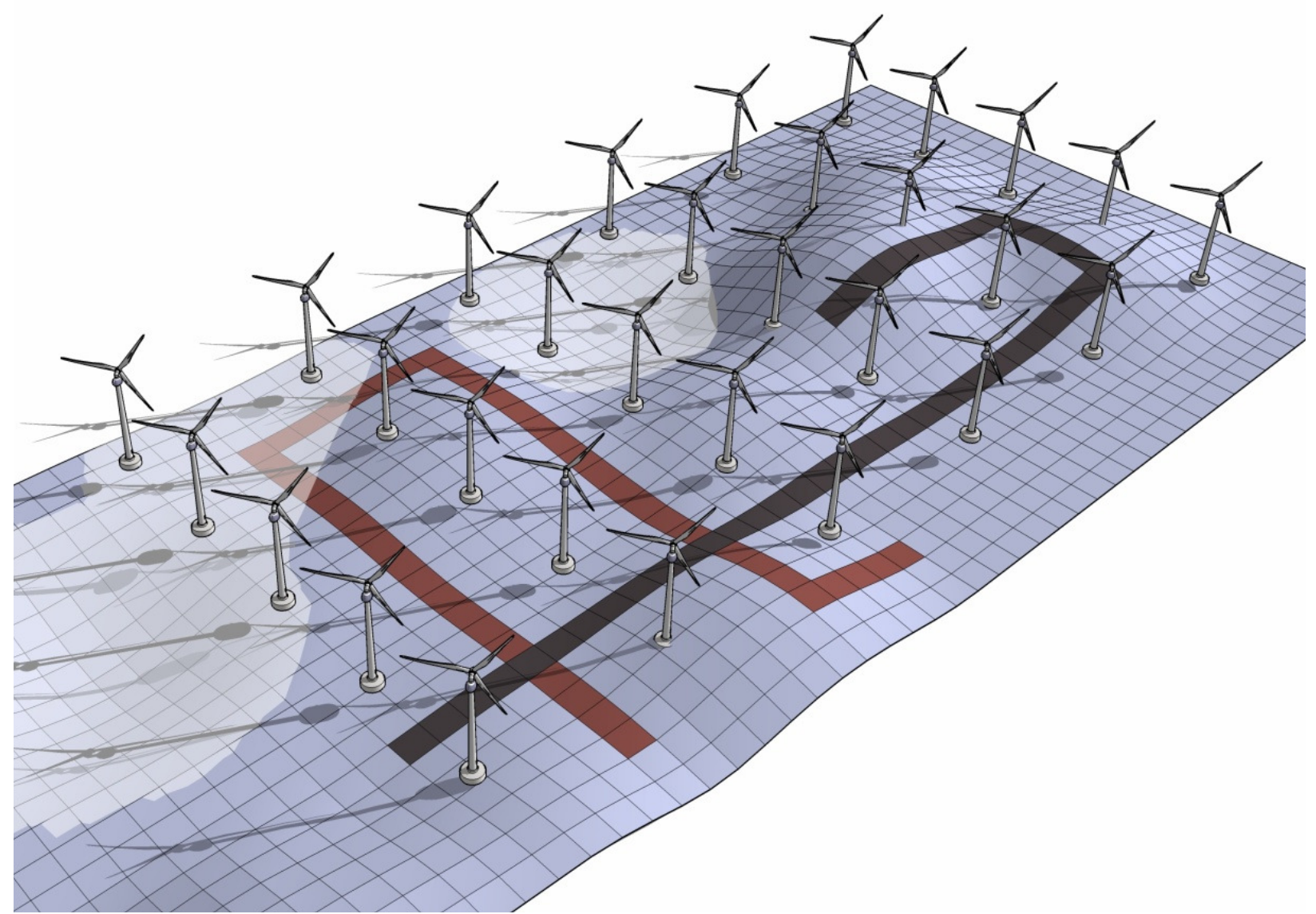

Figure 2: Site Planning for Wind Farm Construction showing two different alternate access road construction sequences

Having the layout of the construction site, the survey team starts setting out the plan and the route for the roads in the construction site using GPS to determine the elevation of the benchmarks to be used after that by the total station in setting the road alignment. The simulation starts by a QUEUE (one of the main STROBOSCOPE modeling elements representing resources) called "SrvyTm" which stands for the survey team that will perform a task called "StgOut" which was discussed above. After the previously mentioned task is done there are two possibilities, the first is that the road segment to be aligned could be a cut section and the second is that it could be a fill section. A COMBI (which is another STROBOSCOPE modeling elements representing events) activity is being introduced under the name of "AssgnCtorFl" to assign whether the segment under construction would be cut or fill. This was done by defining two arrays one under the name "station" in which the values of cuts and fills were defined by positive and negative signs based on the nature of this section (i.e. cut sections are negative and fill sections are positive), it is worth mentioning that these values were assigned to the resource "RdSgmnts" and being a characterized resource, signs are irrelevant. The positive and negative signs were used which converted these signs into zeros and ones in order to be able to interpret these values in STROBOSCOPE. The other array was called "Orgvalue" in which the amount of cut and fill of the section was introduced. Having those two arrays the values were assigned to the QUEUE under the name "RdSgmnts" and the values of zeros and ones were assigned for the subtype in the same resource queue called "cf" while the value of the quantities of cut and fill were in the syubtype "value". The arrays were converted to resource subtypes as follows: 
CHARTYPE Stations cf value; /ST

SUBTYPE Stations st1 1 200;

SUBTYPE Stations st2 0 400;

SUBTYPE Stations st3 1800 ;

A DYNAFORK (which is a STROBOSCOPE element used for routing resources) was used after the sections were available in the QUEUE "RdSgmnts" to route the segments to be constructed based on the value of "cf". For "cf" equal to one, the section is considered to be a fill section and for "cf" zero the section is considered a cut section. The operation of cutting the road differs than that of filling section and the duration for these two operations differ due to the difference in the productivity of each operation. In case of cut work in a particular section, the loader starts to cut the soil from the road segment until it reaches the stake limiting the road corridor. So for this operation a loader was used and a truck to dump the hauled soil. As for the fill section the technique depends on filing the section on $25 \mathrm{~cm}$ increments and then compacting of one increment before starting the next $25 \mathrm{~cm}$ layer. Overlaying the base course layer takes place after finishing cutting and filling the sections and then watering all over the segment to fill up the voids and start compaction again. After compaction takes place, samples are taken in order to make sure that the road has the required strength. This step in simulation is represented by a DYNAFORK and routing for the road segment is based on the rejection rate of the compaction specimen and is modeled as:

$\begin{array}{lc}\text { STRENGTH } & \text { Link15 'RdSctn.cf }==0 \text { '; } \\ \text { STRENGTH } & \text { Link16 'RdSctn.cf }==1 \text { '; } \\ \text { DRAWDUR } & \text { lk108 'lk108.value'; } \\ \text { DURATION } & \text { CtgSoil 'lk108.SumDrawDur'; }\end{array}$

After having the segments ready, construction of wind towers can then start, assuming that each segment will have four wind towers, the first step in their construction is getting the foundations ready. Installing reinforcement for the foundation is done by the steel crew and using the steel reinforcement. With the rebar in place, and forms situated around the outer edges, concrete is then poured using the concrete trucks leaving just the bolts sticking up above the steel reinforcements. After trucks deliver the components to assemble the crane, the crew assembles the crane. Turbine tower components start arriving. Once the parts are on site, the assembly of the tower can begin. After these steps are performed a new segment for the roads start and the above mentioned process is carried on again until a condition is given to stroboscope to stop simulation when the current count of the resources in the segments queue reaches a certain value. Table 1 shows a description of the main modeling elements used in the model shown in Figure 3. 
Table 1: The Various Elements used in the model

\begin{tabular}{|c|c|}
\hline Overlng & Overlaying the sub base course layer after cutting or filling the sections \\
\hline SITrk & Soil truck used to get the course sub base aggregates to the construction site \\
\hline Wtrng & Spreading water over the road segment \\
\hline RdSbase & A queue representing the road after sub base and before watering \\
\hline WtrTrk & Water truck having water that would be spread on road segments before compaction \\
\hline StgOut & Setting out the road \\
\hline RdRdy & Road ready for over laying the sub base after cutting or filling it \\
\hline CtTrk & Truck used to convey the soil cut from cut sections \\
\hline Sgmnt25 & Queue represents the $25 \mathrm{~cm}$ layers that would be used in fill of fill sections \\
\hline RdSctn & Dynafork used to route the segments and determine whether it is cut or fill \\
\hline Fill & Resource conveying the road segments to be filled \\
\hline Cut & Resource conveying the road segments to be cut \\
\hline CtgSoil & The activity of cutting the soil in the cut sections \\
\hline AssgnCtorFl & The activity of assigning the road segment to be a cut or fill section \\
\hline RdSgmnts & The queue that have the road segments to be cut and filled \\
\hline TwrPrts & The queue contain the part of the towers \\
\hline TwrLdg & The activity of unloading the tower parts in the construction site \\
\hline TwrTrk & The truck carrying the tower parts \\
\hline ElcrclCbls & The queue representing the electrical cables that would be running around the towers \\
\hline LdgCbls & The activity of unloading the cables form the tucks to the construction site \\
\hline ElcrclCblTrk & The queue that represents the trucks carrying the electrical cables \\
\hline ElcCrw & The electrical crew \\
\hline ElclWks & The activity of laying the electrical cables in the excavated trenches \\
\hline Ldr1 & Loader used in cutting the soil \\
\hline ExcTrnch & Excavating the trenches for the electrical cables \\
\hline Ldr2 & Loader used in excavating trenches for the electrical works \\
\hline ExcElcrcl & The activity of excavation the trenches for electrical cables \\
\hline Curing & An activity representing the curing of concrete for the foundation \\
\hline Ftgs2 & A queue having the number of foundations that are poured and require curing \\
\hline Cmpctn & An activity that represents compaction of the $25 \mathrm{~cm}$ layers in fill sections \\
\hline RdSgnt & A queue represents the road segments that would require compaction \\
\hline SoilTrk & Soil trucks that convey the soil used in filing the road segments \\
\hline FllgSoil & The activity of filling the soil in fill sections \\
\hline FnshdTwrs & A queue represents the number of towers finished \\
\hline SmCrn & Small crane \\
\hline TrbnPrts & Queue having the turbine parts that are assembled and then lifted to the top of the tower \\
\hline Twrs & A queue represents the number of towers finished with out of the hub \\
\hline TwrCrw & Crew for tower construction \\
\hline $\mathrm{BgCrn}$ & Big Crane \\
\hline TwrAssmbly & The activity of constructing the tower \\
\hline FnshdFtgs & A queue represents the towers location which are ready to start tower construction \\
\hline EqpEntry & Equipment entering the site \\
\hline CncrtTrk & Trucks having the concrete used in foundations \\
\hline Ftgs & A queue representing the number of reinforced foundations before pouring concrete \\
\hline PrgCncrt & The activity of pouring the concrete \\
\hline SrvyTm & The survey team \\
\hline
\end{tabular}




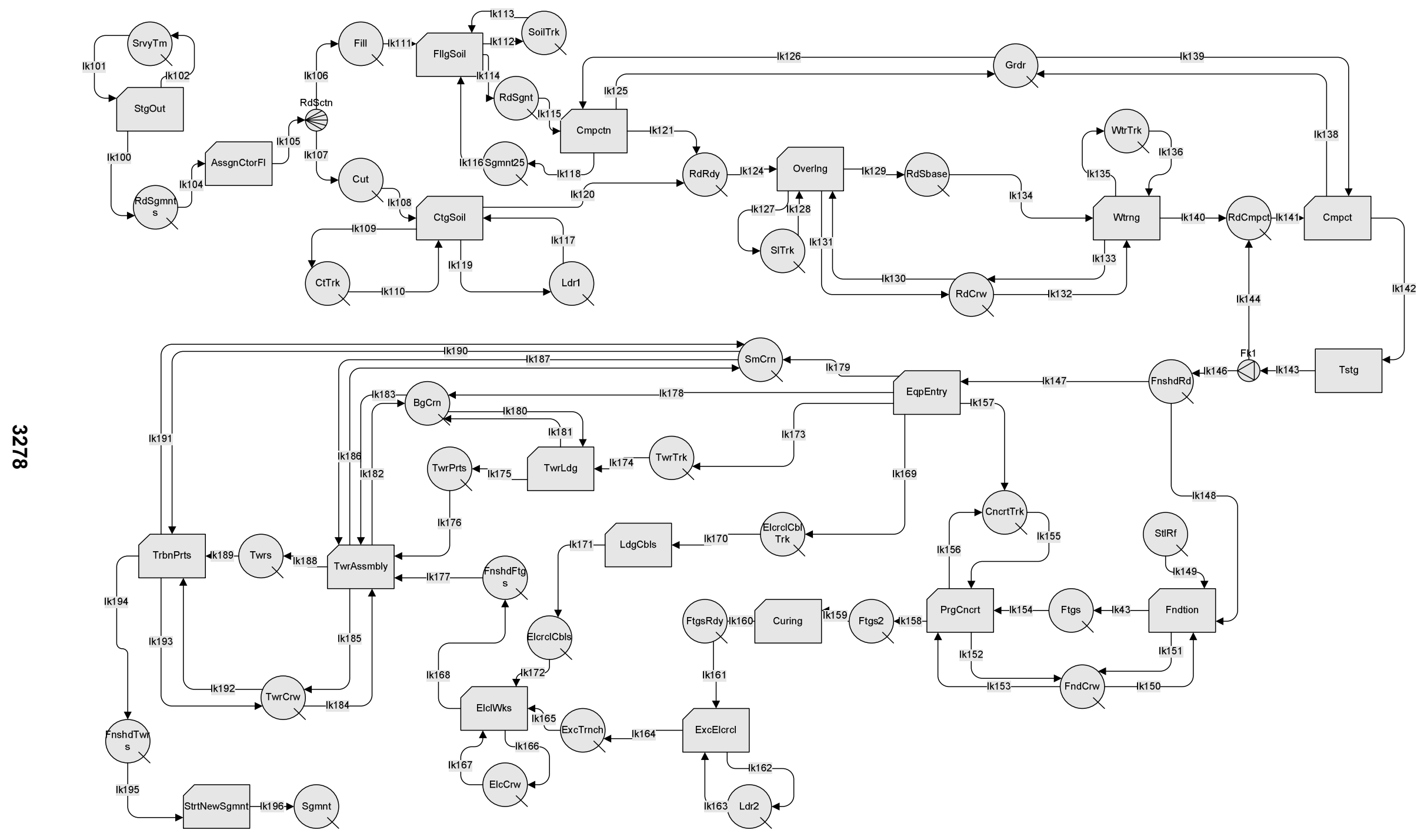

Figure 3: The Site and Utilities SubModel 


\section{SCALABILITY AND SAMPLE SIMULATION RESULTS}

In this section we present a sample example of the model. Consider a potential site for a wind farm with a number of wind turbines such as the one shown in figure 4 below. The wind farm site shows the location of the wind towers. One of the key element of the layout design is the minimum turbine spacing insuring that the turbines are not being used outside their design conditions and which is dependent on the nature of the terrain and the wind rose at a site. Once this has been defined, a design process known as micrositing is carried out where the goal is to optimize the energy production while minimizing infrastructure. It is widely accepted that the more dominant criteria is wind production and not infrastructure costs. Nevertheless the same layout can be constructed using different access road routes ( 2 of which are shown in figure 4). The selection of the appropriate access road route is obviously also dependent on the shape of the site. For rectangular shaped sites with a grid layout for the wind turbines, the longer the site the shorter the overall access road routes taken in the longitudinal direction. However the traverse direction may become more feasible as the site's shape becomes closer to a square.

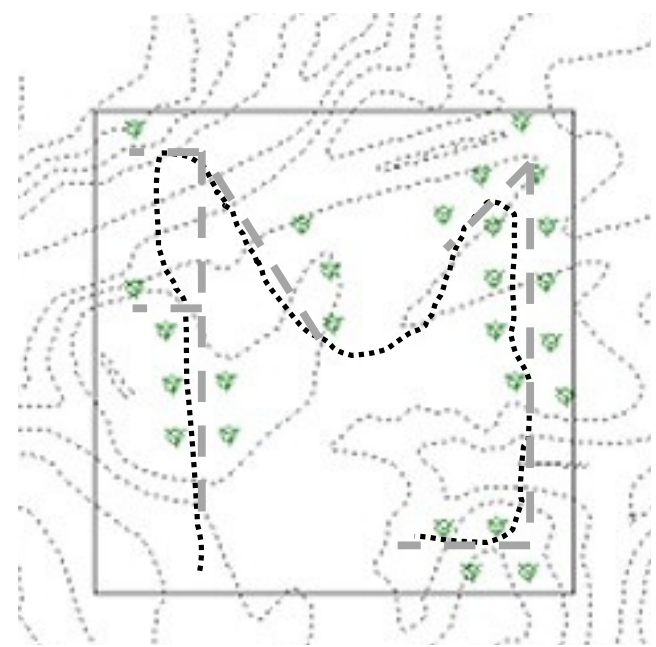

Figure 4: Layout for a wind farm with two distinct possible access road routes

Regardless of the shape of the site, various access road routes can be chosen for any given site, each of which will be able to reach all the wind turbines in order to allow for erection. Figure 5, shows 4 hypothetical access road routes for a specific wind farm site. For each alternate route the existing and the proposed profile are shown along with the mass diagram. Note that in all 4 options the net amount of cut and fill volumes is the same. The only difference between the 4 options is that the distribution of the cut and fill volumes on the stations is different in each alternate access road route. Because of the fact that the volumes of cut and fill are different across the various stations, the duration distribution of the earthwork activities will also be different which will have an impact on the overall duration of the project. This impact cannot be easily calculated or understood without a detailed simulation model such as the one developed in the previous section. 
Nassar, El Masry, and Osman
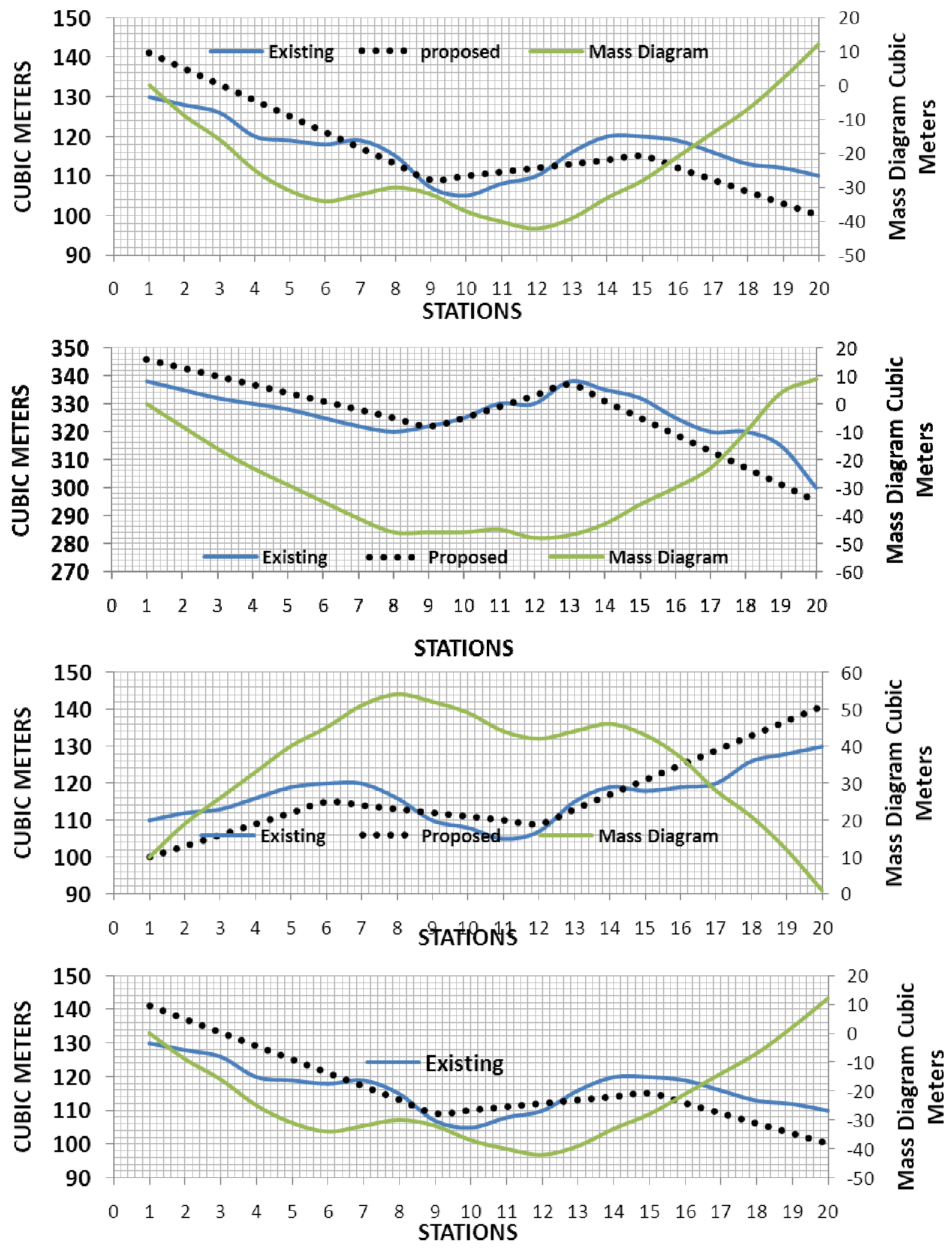

Figure 5: The Profile of Cut and Fill and the Mass Diagrams for the four Alternate Access Road Routes (values are in 1000s) 


\section{Nassar, El Masry, and Osman}

Therefore in order to assess the impact on the various access road routes on the overall total duration of the project, we ran the simulation model described above using the different access road routes as input. For each route an array of the cut and fill volumes was created and input into the model to derive the durations of the earthwork activities and in turn the duration of the overall project. Typical stochastic durations were defined for the various activities in the simulation model. The stroboscope model was run with 1000 replications for each of the access road route options and the results are shown in figure 6 below. The figures presented are histogram of the total project duration after it has been converted to days and they show a great discrepancy in the overall project duration. Note that the average project duration varied from 350 days to 458 days depending on the access road route selected. Although the different access road routes had the same cumulative net cut and fill volumes as shown in their mass diagrams their effect on the overall project duration is significantly different. This is primarily due to the distribution of the rest of the project activities resulting in idle times for critical resources that cannot be utilized until sections of the access road have been completed.
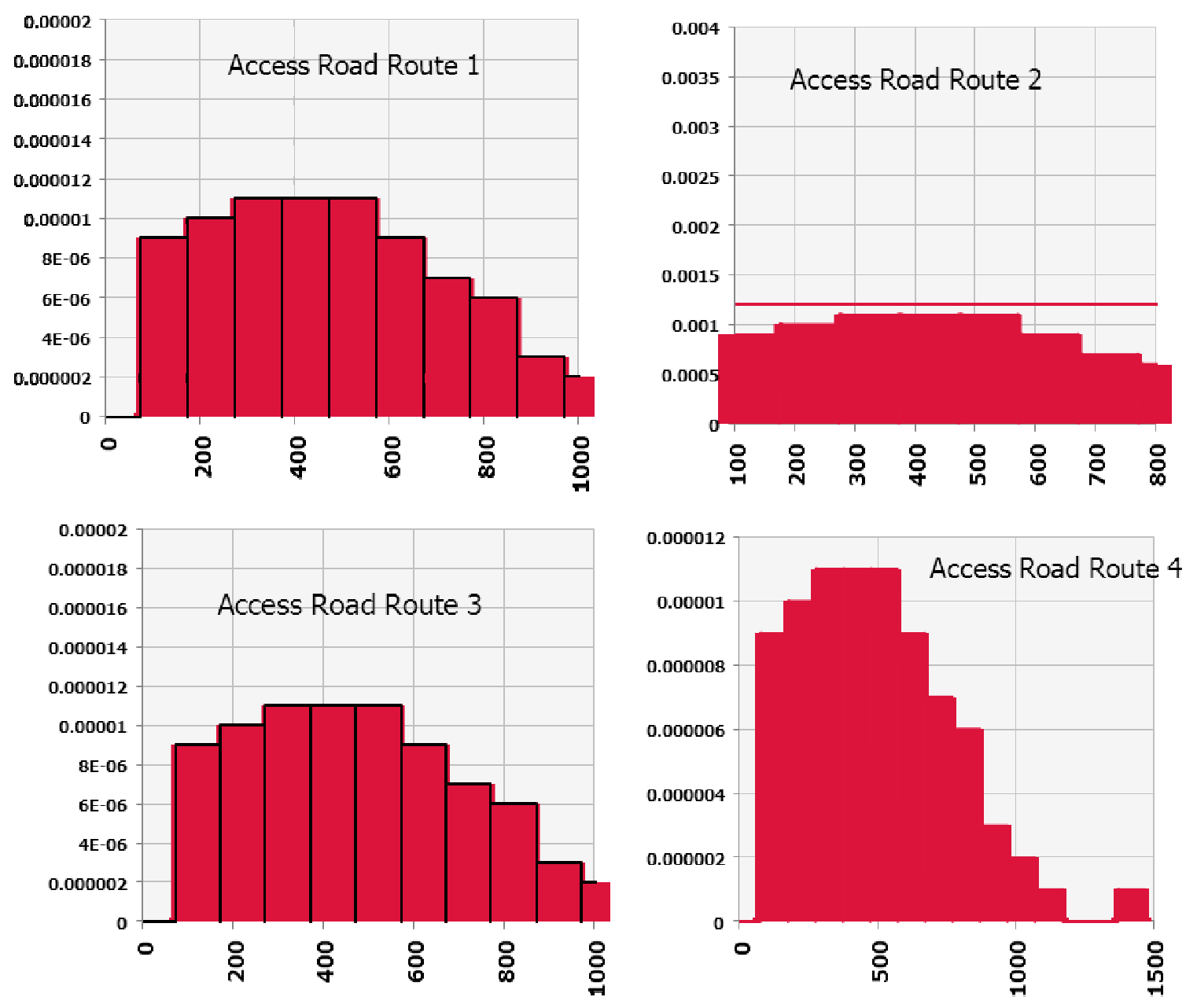

Figure 6: The distributions of the results of simulating the four Alternate Access Road Routes

\section{CONCLUSIONS AND FUTURE WORK}

This paper presented a state of the art research towards building a rigorous understanding of the construction processes involved in the construction of wind farms. This includes both the processes involved throughout the construction cycle of the entire wind farm as it relates to specific towers as well as the 


\section{Nassar, El Masry, and Osman}

overall construction and development of the entire wind farm site. The paper presented an integrated framework for planning wind farm construction activities and then a detailed description of the site work sub model was provided. A simulation model was developed using STROBOSCOPE and the model was used to demonstrate the effect of access road selection may have on the overall project duration. Future research areas include investigating the combined effect of wind and access road selection as well as the integration of other physically-based aspects into the simulation model.

\section{REFERENCES}

Carns, D.W., and W.J. Bender. 2010. Construction of a wind farm and case study. Central Washington University, Ellensburg, Washington. Available via <http://ascpro0.ascweb.org/> [accessed April 2, 2010].

Carns, D.W., and W.J., Bender. 2009. A case for wind farm construction. Wind Systems Magazine. September/October..

Matinez,J.C.1996.STROBOSCOPE State and resource based simulation of construction processes. Ph.D.thesis, Department of Civil Engineering, Michigan University.

Wisconsin Energy Center. 2007. The Self-Erecting Wind Turbine: Feasibility and Preliminary Design. Project summary developed by the Energy Center of Wisconsin for Xcel Energy. Available via $<$ wWw.xcelenergy.com> [Accessed March 7th 2010]

\section{AUTHOR BIOGRAPHIES}

KHALED NASSAR is an associate professor at the American University in Cairo (AUC). Prior to joining AUC, he was on the faculty of Bradley University in Peoria, Illinois, the University System of Maryland, as well as the chair of the department of architectural engineering at the university of Sharjah. He has taught and conducted research projects for the Illinois department of transportation and Caterpillar Inc, as well as NSF. He received a Ph.D. from Virginia Tech and worked for several years in the building industry. He has had several years of teaching experience in field of construction and architecture. His research interest includes computer applications in design and construction as well as simulation and visualization. His email address is <knassareaucegypt. edu>.

MOHAMED EL MASRY is a graduate student and research assistant with the Department of Construction and Architectural Engineering at the American University in Cairo, Egypt. He graduated from the Department of Civil Engineering, Cairo University in 2008. His email address is $<$ m_elmasryeaucegypt.edu>.

HESHAM OSMAN is an Assistant Professor with the Construction Management Group at the Department of Structural Engineering, Cairo University, Egypt. He is also an adjunct faculty at the Construction Management program at Nile University, Egypt. His research interests include urban infrastructure asset management and construction management of renewable energy projects. He received his $\mathrm{PhD}$ from the University of Toronto in 2007. His email address is <hmosmanenileuniversity . edu.eg>. 